\title{
Effect of Storage on Rheology of Water-Soluble, Chelate-Soluble and Diluted Alkali-Soluble Pectin in Carrot Cell Walls
}

\author{
Joanna Mierczyńska • Justyna Cybulska • \\ Piotr M. Pieczywek • Artur Zdunek
}

Received: 7 February 2014 / Accepted: 19 August 2014 /Published online: 3 September 2014

(C) The Author(s) 2014. This article is published with open access at Springerlink.com

\begin{abstract}
The properties and functionality of pectins from plant cell walls depend on their structure. Therefore, the objective of this work was to determine the rheological properties of pectins extracted from plant cell walls with different solvents in relation to postharvest storage time. Water (WSP), chelate (CSP) and diluted alkali (DASP) soluble pectins were studied, taken from carrot cell walls ('Nerac' variety), at harvest and at five time points during storage. The rheology of pectins was studied in relation to flow properties and viscosity, and the storage effect was studied in relation to enzyme activity. The results showed that rheology of pectins depend on the solvent used for extraction. The viscosity of each pectin fraction increased during storage. WSP had the highest viscosity (maximum 0.045 Pas) compared to CSP (0.023 Pas) and DASP (0.011 Pas). DASP revealed thixotropic properties that increased from $3 \%$ at harvest to $14 \%$ after 5 months of storage. Flow behaviour of DASP did not change with storage time, whereas WSP and CSP showed a change from dilatant to pseudoplastic flow. The changes in rheological properties may be related to an enzymatic-induced molecular transformation, which promotes a gelling ability.
\end{abstract}

Keywords Pectins $\cdot$ Cell wall $\cdot$ Rheology $\cdot$ Flow $\cdot$ Thixotropy $\cdot$ Carrot

Electronic supplementary material The online version of this article (doi:10.1007/s11947-014-1392-9) contains supplementary material, which is available to authorized users.

J. Mierczyńska · J. Cybulska • P. M. Pieczywek · A. Zdunek $(\bowtie)$

Institute of Agrophysics, Polish Academy of Sciences, ul.

Doswiadczalna 4, 20-290 Lublin, Poland

e-mail: a.zdunek@ipan.lublin.pl

\section{Introduction}

Pectins are a heterogeneous group of polysaccharides abundant in cell walls and the middle lamella of higher plants. Pectins and rheology have been widely studied, since they determine the properties of cell walls, and are used in the food industry as a functional food ingredient (E440 in the European Union) and as a stabilizer for gelling properties in the production of fruit juice, jams, jellies, drinks, sauces, syrups, sugar confectionery, pastries, products and yogurts (Jayani et al. 2005; Mesbahi et al. 2005; Arancibia and Motsenbocker 2006; Cybulska et al. 2011). Pectinases are widespread in higher plants and can also be produced by phytopathogenic microorganisms. Pectinolytic enzymes cause structural changes of pectins, which affect cell walls and overall tissue firmness during maturation and storage (Cybulska et al. 2010). The enzymes are widely used in the food industry as clarification agents for fruit juices, coffee and tea fermentations (Cybulska et al. 2012). In addition, pectinolytic enzymes are involved in maintaining a balanced ecosystem, decomposing organic material from plants (Jayani et al. 2005; AlimardaniTheuil et al. 2011).

The functionality of pectic polymers is connected to their structure. They are rich in galacturonic acid (GalA) and consist of three pectic polymers: homogalacturonan (HG), rhamnogalacturonan I (RG-I) and rhamnogalacturonan II (RG-II) (Willats et al. 2006; Jolie et al. 2010). Pectin substances are composed of $65 \%$ homogalacturonan, with a backbone made of galacturonic acid residues joined in chains by $\alpha-(1,4)$ glycosidic linkages. HG can be estherified at C-6 carboxyl by methyl groups. The functionality of pectin is connected to the structure of HG. The degree of methylation and the degree of acetylation determine the gelation, binding capacity and rheological properties of pectin-based products. When the GalA residues form galacturonan are not methylesterified with C-6 carboxyl, these residues have a negative 
charge and are then able to interact with some ions, such as calcium cations, forming an intermolecular network. This is widely used in the food industry (Caffall and Mohnen 2009). Depending on the degree of esterification, pectins are classified into two major groups: high-methoxyl pectin (HMP) and low-methoxyl pectin (LMP).

The structure and properties of pectin polymers in cell walls are correlated with the action of pectinolytic enzymes. The enzymes cause changes in cell wall construction, leading to a loss of firmness, reducing shelf life and fruit quality. There are three major classes of pectin-degrading enzymes present in nature: pectinmethyleserases, polygalacturonases and lyases (Jayani et al. 2005; Wei et al. 2010). Pectinmethylesterase is able to catalyse hydrolysis of the methyl-esther group with C-6 carboxyl, producing lowmethoxyl pectin chains. Polygalacturonase catalyses hydrolytic cleavage of the $\alpha-(1,4)$ glycosidic linkages and can be found in two isoforms: endo-PG and exo-PG. Pectin lyases (PL) degrade glycosidic bonds without introducing water across the oxygen bridge by $\beta$-elimination. $\beta$-galactosidase ( $\beta$-Gal) and $\alpha$-L-arabinofuranosidase ( $\alpha$-L-Af) are responsible for removing galactosyl and arabinosyl residues from cell wall polysaccharides (Jayani et al. 2005; Wei et al. 2010).

Rheological properties are very important in food technology, as well as in assessing the quality and acceptability of food by consumers. Examination of rheological properties is appropriate to determine the structure and organization of food fluids (Tabilo-Munizaga and Barbosa-Cánovas 2005; Espinosa-Muňoz et al. 2013; Juszczak et al. 2012). Viscosity is one of the basic parameters describing flow behaviour of liquid and semi-liquid food. According to viscosity and fluid resistance to flow as a consequence of applied shear stress, food liquids can be classified as Newtonian and non-Newtonian. Newtonian fluids are defined as liquids with constant viscosity, independent of the shear rate. Newtonian flow behaviour is not frequent for food fluids. In the case of nonNewtonian liquids, rheological properties are dependent on the relationship between shear stress and shear rate. When decrease of viscosity with increase of shear rate is observed, the liquid is called shear-thinning or pseudoplastic. On the other hand, increased viscosity with increasing shear rate is referred to as shear thickening or dilatant (Tabilo-Munizaga and Barbosa-Cánovas 2005). Pseudoplastic and dilatant fluids are also time independent, but there are many food liquids and semi-liquids showing time-dependent behaviour connected with increased (rheopexy) or decreased (thixotropy) of viscosity according to the shearing time. From a technological point of view, the phenomenon of thixotropy has many applications in food processing. The thixotropic effect can be described as destruction of the internal structure during the shear load phase and regeneration of a material organization during the rest phase. Evaluation of the thixotropic effect can predict liquid behaviour during technological processes (TabiloMunizaga and Barbosa-Cánovas 2005; Ma et al. 2014).

Most of the works on pectin extracted from carrot concern biochemical properties and enzyme activity (Christiaens et al. 2012; Houben et al. 2011; Araya et al. 2007; Galindo et al. 2004). The rheological properties of pectin have also been reported by Pagán and Ibarz (1999), Schmelter et al. (2002), Alonso-Mongán et al. (2002), and Espinosa-Muňoz et al. (2013). However, we are aware of no studies on the assignment of rheological properties to pectins of distinct fractions extracted from carrot, although many studies have shown that the molecular structure of pectins from cell walls depends on the solvent used for extraction (Yang et al. 2005, 2006; Zhang et al. 2012). Since pectin structure changes according to the time of postharvest storage, the rheological properties may change too. Therefore, the purpose of our study was to determine the rheological properties of pectins from carrot in relation to storage time and the fraction of the sequential extraction from cell walls (water, chelator and alkali-soluble pectins). Rheology is expressed in terms of flow properties and viscosity whereas the storage effect is studied in relation to the enzyme activity of PME, PG, $\beta$-Gal and $\alpha$-L-Af. This study aims to provide a deeper insight into properties of pectins in cell walls and their usability for industry.

\section{Materials and Methods}

The carrot variety 'Nerac' (Daucus carrota L.cv. Nerac) was harvested and stored at a temperature of about $2{ }^{\circ} \mathrm{C}$ over 5 months. Studies were performed in six stages: directly after harvest (HT) and once a month during the 5 months of storage (T1-T5). At each stage five carrot roots were used. A pulp was made of the whole carrot root for measurement.

\section{Biochemical Properties of Carrot Variety 'Nerac'}

Biochemical characterization of carrot varieties 'Nerac' consisted of water content (dry basis), soluble solids, total acidity and $\mathrm{pH}$. To determine water content, samples were weighed and then dried in an oven at $70{ }^{\circ} \mathrm{C}$ for $24 \mathrm{~h}$, and afterwards at $105^{\circ} \mathrm{C}$ for $3 \mathrm{~h}$; then, the samples were weighed again and the water content was expressed as kilogram of water in fresh samples per kilogram of dry matter after drying. The soluble solid content in degrees Brix was determined using a digital refractometer (Atago Company). Total acidity was determined in reference to PN-90/A-75101/04 "Determination of total acidity" (Zdunek and Cybulska 2011).

\section{Enzyme Extraction and Determination of Enzyme Activity}

Enzyme extraction from the carrot cell walls and determination of enzyme activity were carried out according to the 
method proposed by Wei et al. (2010), with slight modifications. To extract cell wall enzymes, frozen, powdered flesh was stirred into $6 \mathrm{ml}$ of cold $12 \%$ polyethyleneglycol containing $0.2 \%$ sodium bisulphate. Then, the homogenate was centrifuged for $10 \mathrm{~min}$ at $6,000 \times \mathrm{g}$ and the pellets washed in $4{ }^{\circ} \mathrm{C}$ aqueous $0.2 \%$ sodium bisulphate and collected and extracted for PG, PME, $\alpha$-L-Af and $\beta$-Gal. The extraction conditions included $6 \mathrm{~mL}$ of cold extraction buffer [1 M sodium acetate $(\mathrm{pH} 5.2), 1 \mathrm{M} \mathrm{NaCl}, 2 \%(v / v)$ mercaptoethanol, and $5 \%(w / v)$ polyvinylpyrrolidone (PVP)] at $4{ }^{\circ} \mathrm{C}$ for $1 \mathrm{~h}$. The homogenate was centrifuged for $10 \mathrm{~min}$ at $6,000 \times \mathrm{g}$, and the supernatant was used to assay for enzyme activity.

Polygalacturonase (PG) activity was determined according to the reaction of the enzyme extract $(0.2 \mathrm{~mL})$ with $0.8 \mathrm{~mL}$ of $0.5 \%$ polygalacturonic acid in $50 \mathrm{mM}$ sodium acetate buffer (pH 5.2). Then the mixture was incubated at $37^{\circ} \mathrm{C}$ for $2 \mathrm{~h}$. After incubation, $2 \mathrm{~mL}$ of borate buffer ( $0.1 \mathrm{M}, \mathrm{pH} 9.0)$ and $0.3 \mathrm{~mL}$ of cyanoacetamide were added to the reaction mixture, which were boiled for $10 \mathrm{~min}$ and then cooled in ice. Absorbance was read at $320 \mathrm{~nm}$. Galacturonic acid was used as standard and the controls for the boiled extract were run in the reaction buffer. One unit of activity was defined as microgram of galacturonic acid and released per gram fresh weight (FW) per minute.

The activity of $\beta$-Gal and $\alpha$-L-Af were measured using $3 \mathrm{mM} p$-nitrophenyl- $\beta$-D-galactopyranoside and $p$ nitrophenyl- $\alpha$-D-arabinofuranoside as substrates, respectively; $0.5 \mathrm{~mL}$ of $0.1 \mathrm{M}$ sodium acetate $(\mathrm{pH} 5.2)$ and $0.5 \mathrm{~mL}$ of substrate were preincubated at $40{ }^{\circ} \mathrm{C}$ for $10 \mathrm{~min}$ before $0.5 \mathrm{~mL}$ of the enzyme extract was added. After incubation at $37{ }^{\circ} \mathrm{C}$ for $30 \mathrm{~min}$, the reaction was stopped by adding $2.0 \mathrm{~mL}$ of $0.5 \mathrm{M}$ sodium carbonate, and the $p$-nitrophenol that was released was then measured spectrophotometrically at $400 \mathrm{~nm}$. A calibration curve was obtained by using free $p$-nitrophenol (PNP) as a standard. Enzyme activity was expressed as nanomoles PNP per gram FW per minute. In all assays, the experiment with boiled enzyme extract was taken as the control.

To determine pectin methylesterase (PME) activity, $1 \mathrm{~mL}$ of crude extract was mixed with $4 \mathrm{~mL}$ of $1 \%$ $(w / v)$ citrus pectin and titrated with $0.01 \mathrm{M} \mathrm{NaOH}$ to maintain $\mathrm{pH} 7.4$ while incubating at $37{ }^{\circ} \mathrm{C}$ for $1 \mathrm{~h}$. One unit of activity was calculated as $1 \mathrm{mmol} \mathrm{NaOH}$ and consumed $\mathrm{g}^{-1} \mathrm{FW} 10 \mathrm{~min}^{-1}$.

\section{Preparation of Alcohol Insoluble Residues}

The cell wall material of carrot was isolated as alcohol insoluble residues (AIR), based on a method described by Renard (2005) with slight modifications. The carrot was crushed and homogenized using a laboratory homogenizer. The pomace was stirred with $70 \%$ ethanol, boiled for
$20 \mathrm{~min}$ and then filtered. The residues were homogenized again in $70 \%$ ethanol for $20 \mathrm{~min}$ and then filtered. The operations were repeated until sugars were eliminated from the sample, which was verified using methods described by Dubois et al. (1956). Finally, the residues were homogenized in acetone before final filtration and then dried overnight at $40{ }^{\circ} \mathrm{C}$.

Sequential Extraction of Pectins, and Determination of GalA and $\mathrm{Ca}^{2+}$ Contents

The samples for determination of the amount of galacturonic acid were prepared using sequential extraction of pectin from AIR. To the sequential extraction of pectin $0.1 \mathrm{~g}$ of sample was added to $9 \mathrm{~mL}$ of water and stirred overnight at room temperature. The sample was then centrifuged $(6,000 \mathrm{rpm}, 15 \mathrm{~min})$, and filtered on a nylon filter; the filtrate was then retained and the pellet was suspended in $5 \mathrm{~mL}$ of CDTA $(0.05 \mathrm{M}, \mathrm{pH} 6.5)$ and stirred for $6 \mathrm{~h}$ at room temperature. After centrifugation $(6,000 \mathrm{rpm}, 15 \mathrm{~min})$ and filtration, the filtrate was retained and the pellet was added to another $5 \mathrm{ml}$ of CDTA and again stirred for an hour. The sample was centrifuged and both CDTA filtrates were combined. The precipitate was suspended in $5 \mathrm{~mL}$ of $0.05 \mathrm{M} \mathrm{Na}_{2} \mathrm{CO}_{3}+$ $20 \mathrm{mM} \mathrm{NaBH}$, stirred for $2 \mathrm{~h}$, and the sample was centrifuged and filtered. The $\mathrm{Na}_{2} \mathrm{CO}_{3}+\mathrm{NaBH}_{4}$ filtrates were mixed.

During the extraction, three fractions of pectin were obtained: WSP — water-soluble pectin, CSP - chelator soluble pectin, DASP — diluted alkali-soluble pectin (Selvendran and O’Neill 1987).

After sequential extraction, sediment was obtained. To analyse the amount of insoluble pectin, hydrolysis of the sediment was carried out using $13 \mathrm{M}$ sulphuric acid (VI)incubation at $25^{\circ} \mathrm{C}$ for $1 \mathrm{~h}$. Sulphuric acid $(1 \mathrm{M})$ was then added, the samples were incubated at $100{ }^{\circ} \mathrm{C}$ for $2 \mathrm{~h}$ and filtered after cooling. The filtrate was neutralized with $\mathrm{NaOH}$ solution.

The amounts of galacturonic acid and calcium ions were analysed according to a colorimetric reaction with 3-phenyl phenol and $o$-cresolphthalein complexone, respectively, using continuous flow analyser (CFA), SanPlus (Skalar, The Netherlands).

\section{Determination of Degree of Methylation}

Degree of methylation (DM) was determined in freezedried WSP fraction using infrared spectroscopy with Fourier transformation (Manrique and Lajolo 2002). Degree of methylation was estimated as a ratio of area of wavelength band at about $1,750 \mathrm{~cm}^{-1}$ responsible for oscillations of $\mathrm{C}-\mathrm{O}-\mathrm{C}$ in the ester linkage at $\mathrm{C} 6$ in homogalacturonan 
chain and area of a wavelength of about $1,630 \mathrm{~cm}^{-1}$ responsible for oscillations of carboxyl groups.

\section{Determination of Rheological Properties of WSP, CSP and DASP}

To study the rheological properties of WSP, CSP and DASP, aqueous solutions of pectin fractions were lyophilized and then $5 \%$ solutions of freeze-dried WSP, CSP and DASP were prepared. Measurement of rheological properties was done using a R/S Plus rheometer (Brookfield, Middleboro, MA) with a cone-plate sensor. Measurements were taken at $20^{\circ} \mathrm{C} \pm$ $0.5^{\circ} \mathrm{C}$ using constant shear rate $\left(1,200 \mathrm{~s}^{-1}\right)$ and variable shear rate.

To determine the rheological behaviour of various pectin fractions, flow curves (shear stress in Pa versus shear rate in $\mathrm{s}^{-1}$ ) were collected; the Power law model, also called the Ostwald de Waele's model, was applied. This two-parameter rheological model provides the simplest way to describe the experimental flow curves for shearthinning fluids (Penna et al. 2001; Plaskota 2004). The model is given as:

$\sigma=\mathrm{K} \gamma^{\mathrm{n}}$

where $\sigma$-shear stress (Pa), $K$-consistency index $\left(\operatorname{Pas}^{\mathrm{n}}\right)$, $\gamma$ - shear rate $\left(\mathrm{s}^{-1}\right), n$-flow behaviour index.

According to the flow behaviour index, fluids can be classified as pseudoplastic or dilatant. If $n<1$, a liquid can be called shear-thinning or pseudoplastic. On the other hand, $n>1$ corresponds to a shear-thickening or dilatant fluid, while $n=1$ corresponds to a Newtonian fluid with $K$ as the constant viscosity (Liang et al. 2012).

The relationship between shear stress and shear rate allows a thixotropic effect to be determined. The thixotropic phenomenon can be described as a reversible transition from gel to sol as the result of applied force, and a return to gel state after the force is removed. Generally, the term thixotropy is connected with complex structures of material (Lee et al. 2009; Ottone et al. 2009). To determine magnitude of thixotropic effect, we calculated the surface area of the hysteresis loop. The size of hysteresis loop is related to the size of the thixotropic effect; the stronger the thixotropic properties, the greater surface area (Dolz et al. 2007).

\section{Statistical Analysis}

Data were tested through analysis of variance (ANOVA), and significant differences were determined at $p<0.05$ using statistical software STATISTICA 10.

\section{Results and Discussion}

\section{Biochemical Analyses}

Enzyme activity and degradation of pectin in carrot cell walls were examined during 5 months of storage in a cold atmosphere. It was found that the chemical composition of the carrot variety 'Nerac' changed significantly during this period (Table 1).

With storage time, water content in carrot tissues decreased. At the time of harvest (HT), water content (dry basis) was $9.24 \mathrm{~g} / \mathrm{g}$, and decreased to $8.0 \mathrm{~g} / \mathrm{g}$ at T5. Storage can cause pronounced water loss; however, high humidity in a cold room (about $70 \%$ ) actually prevented dehydration, causing only a slight decrease of the water content (Galindo et al. 2004).

Loss of water during postharvest storage also led to an increase of sugar content in the extract from 7.7 in the HT term to 10.2 in the fourth term, measured in Brix (Table 1). The $\mathrm{pH}$ of the solution also decreased with time of storage, which resulted in an increase of total acidity. The changes in sugar content and total acidity may also relate to the degradation of pectin as a result of enzymatic releasing of free galacturonic acid and other sugar residues. During storage, activity of pectinmethylesterase (PME) remained at a constant level, while activity of other three enzymes increased (Table 2).

A high content of branched components of pectin was observed, such as RG-1 in carrot (Houben et al. 2011). Recent study showed in details the branching of CSP and DASP fractions in carrot which diminished with storage time (Cybulska et al. 2014). The reduction of the neutral sugar amount in side chains of pectin, resulting in diminishing bands at 1,145, 1,105, 1,070, 1,015, 950, $924 \mathrm{~cm}^{-1}$ of FTIR spectra (shown in the supplementary material in Fig. S1), could be connected with the high activity of $\beta$-galactosidase ( $\beta$-Gal) and $\alpha$-L-arabinofuranosidase ( $\alpha$-Af). The activity of these enzymes increased during postharvest ripening (Table 2), suggesting that in carrot both galactose and arabinose residues would be released from the RG-1 chain. $\alpha$-Af showed the highest increase of activity during storage. It has been proven that highly branched chains present in immature fruit can protect cell wall polysaccharides from early PG attack, but removing neutral sugars from side chains results in increased sensitivity of compounds to the action of PG (Goulao and Oliveira 2008). Increase of PG activity in carrot during storage may also be a consequence of increased $\alpha$-Af and $\beta$-Gal activity. In cell walls, the arabinans work as spatial regulators of the proximity of homogalacturonan domains (Harholt et al. 2010). This regulation may prevent the formation of $\mathrm{Ca}^{2+}$ mediated interactions between smooth galacturonic acid polymers. Therefore, the removal of arabinan may induce stiffening of the cell wall. 
Table 1 Biochemical properties of carrot variety 'Nerac' during postharvest storage

$H T$ stage directly after harvest, $T 1$ the first month of storage, $T 2$ the second month of storage, $T 3$ the third month of storage, $T 4$ the fourth month of storage, $T 5$ the fifth month of storage

\begin{tabular}{llllc}
\hline Term & Water content (dry basis) $[\mathrm{g} / \mathrm{g}]$ & $\mathrm{pH}$ & Titratable acidity $[\mathrm{g} / 100 \mathrm{~g}]$ & $\begin{array}{c}\text { Soluble solid } \\
\text { content }\left[{ }^{\circ} \text { Brix }\right]\end{array}$ \\
\hline HT & $9.24 \pm 0.20$ & $6.21 \pm 0.02$ & $0.022 \pm 0.003$ & $7.7 \pm 0.1$ \\
T1 & $7.55 \pm 0.04$ & $6.22 \pm 0.06$ & $0.026 \pm 0.001$ & $9.0 \pm 0.1$ \\
T2 & $7.12 \pm 0.34$ & $5.96 \pm 0.08$ & $0.031 \pm 0.002$ & $9.5 \pm 0.1$ \\
T3 & $7.43 \pm 0.10$ & $6.05 \pm 0.01$ & $0.029 \pm 0.003$ & $9.9 \pm 0.1$ \\
T4 & $7.07 \pm 0.17$ & $5.95 \pm 0.03$ & $0.038 \pm 0.002$ & $10.2 \pm 0.1$ \\
T5 & $8.00 \pm 0.11$ & $5.96 \pm 0.03$ & $0.033 \pm 0.001$ & $9.4 \pm 0.1$ \\
\hline
\end{tabular}

PME activity remained constant during storage. Since the enzyme is responsible for hydrolytic cleavage of the methoxyl group $\mathrm{OCH}_{3}$ at $\mathrm{C} 6$, resulting in the formation of low-methoxyl pectin chains, its activity is strictly correlated with the degree of methylation. The DM of WSP extracted from carrot variety 'Nerac', estimated from FTIR presented in supplementary material S1 (Fig. S1 a) as the ratio of area under the peak at about $1,750 \mathrm{~cm}^{-1}$ and area under $1,630 \mathrm{~cm}^{-1}$, was between $71.8 \%$ in the third term of storage and $78.8 \%$ in the second term of storage (Table 2). These results are slightly higher than the $60 \%$ previously reported by Christiaens et al. (2012) and the 58-69 \% reported by Cybulska et al. (2014), and deviates significantly from the result obtained by Galindo et al. (2004), where DM was estimated between 36 and $39 \%$. However, these other studies also found DM remained relatively stable during storage. The high degree of methylation in WSP obtained in this study may be related to synthesis of new highmethylated pectins, which was postulated by Fisher and Amado (1994). In this study, an increase of total GalA content was observed from 228 at harvest to $329 \mu \mathrm{m} / \mathrm{mg}$ AIR after 5 months of storage (Fig. 1). Postharvest synthesis of GalA was observed also in pectins extracted from carrots of 'Karotka' cultivar by Cybulska et al. (2014), associated with a slight decrease of DM and relatively constant PME activity. This suggests that, despite the fact that PME activity remained at a constant level, synthesis of new high-methylated pectins caused DM to remain relatively stable at a high level.

PME activity is determined and controlled in a cyclic manner by fluctuations in the concentration of $\mathrm{H}^{+}$ions in the cellular environment. It seems that neutral $\mathrm{pH}$ can be optimum for enzyme action, but in some cases protons are released as a result of biochemical reactions connected with ripening, which can lead to $\mathrm{pH}$ reduction. A lower $\mathrm{pH}$ can activate glycosidases and transferases, which can lead to a decrease of $\mathrm{H}^{+}$ion concentration and an increase of local $\mathrm{pH}$. In this way, $\mathrm{pH}$ becomes neutral, i.e., optimal for PME action. This leads to enzyme reactivation and a new cycle of PME activity. These processes are dependent on changes in hydrogen ion concentration (Giovane et al. 2004). Thus, a changing degree of methylation is a consequence of fluctuations in PME activity.

PME activity in plant cell walls can lead to two diametrically different effects. First of all, it can lead to improved structure of cell wall components and form stable gels as a result of the release of non-esterified carboxyl groups interacting with calcium cations. On the other hand, protons released from the reaction catalysed by PME can activate hydrolases connected with the loosening of cell wall structure (Giovane et al. 2004). PME is able to catalyse pectin demethylation and in this way PME prepares substrate for polygalacturonase. PG can catalyse hydrolytic cleavage of $\alpha$ $(1 \rightarrow 4)$ only in low-methylated pectin chains (Arancibia and Motsenbocker 2006). Therefore, increased PME activity during storage can be explained as a consequence of early PME action in the homogalacturonan chain.

The WSP pectin fraction is composed of polymers weakly linked to the cell wall, mainly by non-covalent bonds. In the CSP fraction, pectins are cross-linked with ionic bonds, and in
Table 2 Enzyme activity of carrot variety 'Nerac' and degree of methylation during postharvest storage. Mean values with standard deviations

$H T$ stage directly after harvest, $T 1$ the first month of storage, $T 2$ the second month of storage, $T 3$ the third month of storage, $T 4$ the fourth month of storage, $T 5$ the fifth month of storage

\begin{tabular}{llllll}
\hline Term & Enzyme activity & & & $\begin{array}{l}\text { Degree of } \\
\text { methylation [\%] }\end{array}$ \\
\cline { 2 - 5 } & $\begin{array}{l}\text { PME }[\mu \mathrm{mol} \mathrm{NaOH} / \mathrm{g} \\
\text { FW min] }\end{array}$ & $\begin{array}{l}\text { PG }[\mu \mathrm{g} \mathrm{GalA} / \mathrm{g} \\
\text { FW min] }\end{array}$ & $\begin{array}{l}\beta \text {-Gal [nmol } \\
\text { PNP/g FW min] }\end{array}$ & $\begin{array}{l}\alpha \text {-Af [nmol PNP/g } \\
\text { FW min] }\end{array}$ & \\
\hline HT & $1.8 \pm 0.11$ & $4.4 \pm 0.73$ & $1.9 \pm 0.15$ & $2.1 \pm 0.41$ & 75.8 \\
T1 & $2.1 \pm 0.23$ & $4.3 \pm 0.80$ & $1.8 \pm 0.16$ & $4.2 \pm 0.09$ & 73.7 \\
T2 & $2.1 \pm 0.18$ & $6.4 \pm 1.08$ & $2.0 \pm 0.09$ & $4.5 \pm 0.61$ & 78.8 \\
T3 & $2.1 \pm 0.10$ & $4.3 \pm 1.41$ & $3.2 \pm 0.06$ & $7.5 \pm 0.14$ & 71.8 \\
T4 & $2.1 \pm 0.01$ & $10.2 \pm 2.30$ & $3.1 \pm 0.06$ & $9.7 \pm 0.83$ & 72.1 \\
T5 & $2.2 \pm 0.03$ & $7.6 \pm 0.14$ & $2.3 \pm 0.11$ & $10.8 \pm 0.83$ & 73.5 \\
\hline
\end{tabular}




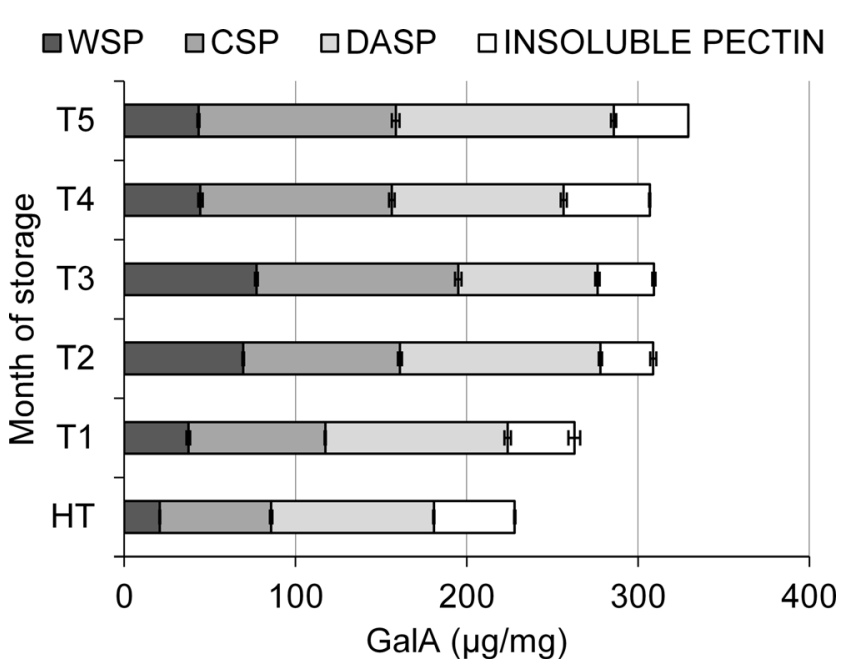

Fig. 1 Galacturonic acid (GalA) content in pectin fractions from 'Nerac' carrot during storage. $H T$ stage directly after harvest, $T 1$ the first month of storage, $T 2$ the second month of storage, $T 3$ the third month of storage, $T 4$ the fourth month of storage, $T 5$ the fifth month of storage

the DASP fraction polysaccharides are connected with the cell wall by covalent ester bonds (Christiaens et al. 2012). As a result of PG activity, free galacturonic acid residues are released (Torres et al. 2011). Figure 1 shows galacturonic acid content in various fractions of pectin in carrot cell walls. The total amount of GalA in cell walls increased during the storage, probably as a consequence of new pectin synthesis. Contrary to this, the content of GalA in pectin fractions varied. In the CSP fraction, GalA increased with time of storage, while in the DASP and WSP fractions it increased till the second term (DASP) and the third term (WSP), and then began to show a decreasing trend. This can lead to reduced content of water-soluble polysaccharides and an increase in the amount of CDTA and $\mathrm{Na}_{2} \mathrm{CO}_{3}$ soluble pectin (Deng et al. 2005).

\section{Rheology}

Figure 2 presents exemplary flow curves for three fractions of pectin obtained experimentally. For WSP and CSP fractions, upward flow curves showed the same course as downward flow curves, i.e., no hysteresis was observed. Contrary to this, in the DASP fraction the upward and downward flow curves formed a loop. Moreover, a more instable course was observed for the DASP flow curves. Generally, the shear stress for the DASP fraction was lower than in the CSP and WSP fractions.

Table 3 presents the Power law parameters from the best-fit curve. Experimental curves obtained for the CSP fraction were best described by this model $\left(R^{2} \sim 0.99\right)$. Data for DASP fraction indicated the purest agreement with the Power law model; however, in most cases, the $R^{2}$ was still greater than 0.9. Thus, we used it to visualize the flow properties (Fig. 3).

According to flow behaviour index $n$, presented in Table 3 , pectin fractions showed both pseudoplastic (when $n<1$ ) and

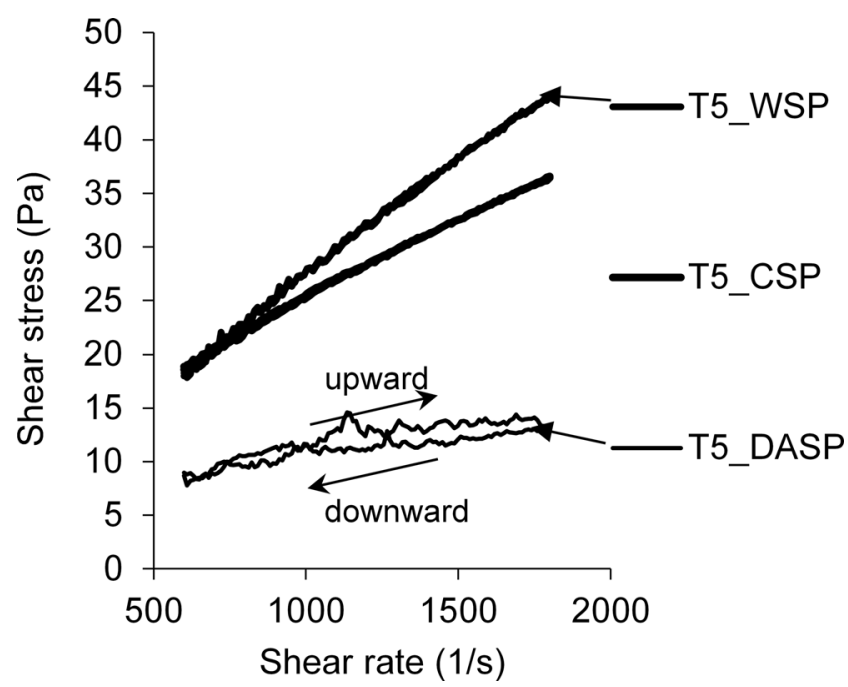

Fig. 2 Representative experimental shear stress vs. shear rate relationship, upward and downward flow curves for three fractions of pectin in six terms of storage. $T 5$ the fifth month of storage

dilatant properties (when $n>1$ ). The DASP fraction in each of the terms showed pseudoplastic behaviour. The WSP fraction presented pseudoplastic flow in the second to fifth terms of storage and dilatant flow in the HT stage. However, in the first term of storage, in the upward curve flow the behaviour index was 1.16 and 0.66 in the downward curve, which means that the samples showed dilatant behaviour connected with an increase in the shear rate. Similarly to the WSP fraction, in the fourth term of CSP fraction flow the behaviour index in the upward curve was 1.04 and 0.99 , indicating lower pseudoplasticity in the upward curve than in the downward curve. Dilatant behaviour of CSP was presented in the HT to the third terms of storage, while pseudoplastic flow was shown in the fifth stage.

Figures $3 \mathrm{a}-\mathrm{c}$ show changes in the flow of pectin fractions at different times of storage. It can be noticed that in each pectin fraction there was a positive relation between the shear rate and the shear stress. In each fraction, there was a tendency for the curves to shift up with storage time. This could be related to changes of pectin molecular structure during storage (Cybulska et al. 2014) and by the synthesis of new highmethylated and branched pectin chains over the whole storage period (Fisher and Amado 1994), as it was observed in this experiment as well (Fig. 1).

The ANOVA showed a significant effect $(p<0.05)$ of the term of storage on viscosity in the case of each fraction (Fig. 4). The graph of changes in viscosity in relation to the period of storage shows that the WSP fraction was characterized by the highest viscosity, particularly in the fourth term of storage. The viscosity of DASP increased fairly steadily during the postharvest storage. The CSP fraction did not show any change in viscosity during the first 3 months, and then increased significantly. Changes in viscosity could be associated with enzyme activity. It is shown in Table 2 that activity of $\beta$-Gal and $\alpha$-Af increased during storage. The viscosity of 
Table 3 The Power law model parameters describing rheological properties of pectin fractions

\begin{tabular}{|c|c|c|c|c|c|c|c|}
\hline Sample & $K$ & Number & $R^{2}$ & Sample & $K$ & Number & $R^{2}$ \\
\hline \multicolumn{4}{|l|}{ Upward curve } & \multicolumn{4}{|c|}{ Downward curve } \\
\hline HT_WSP & 0.0013 & 1.1583 & 0.9846 & HT_WSP & 0.0010 & 1.1968 & 0.9880 \\
\hline HT_CSP & 0.0013 & 1.1657 & 0.9910 & HT_CSP & 0.0017 & 1.1293 & 0.9923 \\
\hline HT_DASP & 0.0259 & 0.7585 & 0.9627 & HT_DASP & 0.2790 & 0.7450 & 0.9772 \\
\hline T1_WSP & 0.7376 & 1.1583 & 0.9772 & T1_WSP & 0.2870 & 0.6551 & 0.9743 \\
\hline T1_CSP & 0.0015 & 1.1512 & 0.9962 & T1_CSP & 0.0013 & 1.1643 & 0.9945 \\
\hline T1_DASP & 0.1551 & 0.5386 & 0.9366 & T1_DASP & 0.0708 & 0.6418 & 0.9314 \\
\hline T2_WSP & 0.0731 & 0.7183 & 0.9827 & T2_WSP & 0.0607 & 0.7437 & 0.9894 \\
\hline T2_CSP & 0.0007 & 1.2161 & 0.9955 & T2_CSP & 0.0007 & 1.2116 & 0.9944 \\
\hline T2_DASP & 0.1132 & 0.6616 & 0.9707 & T2_DASP & 0.0433 & 0.7859 & 0.9583 \\
\hline T3_WSP & 0.0416 & 0.8105 & 0.9896 & T3_WSP & 0.0202 & 0.9093 & 0.9893 \\
\hline T3_CSP & 0.0014 & 1.1254 & 0.9962 & T3_CSP & 0.0006 & 1.2360 & 0.9951 \\
\hline T3_DASP & 0.2508 & 0.4537 & 0.8947 & T3_DASP & 0.0421 & 0.6934 & 0.9449 \\
\hline T4_WSP & 0.2929 & 0.7366 & 0.9992 & T4_WSP & 0.3012 & 0.7327 & 0.9998 \\
\hline T4_CSP & 0.0054 & 1.0363 & 0.9988 & T4_CSP & 0.0007 & 0.9914 & 0.9993 \\
\hline T4_DASP & 0.5362 & 0.4479 & 0.9351 & T4_DASP & 0.2643 & 0.5379 & 0.9917 \\
\hline T5_WSP & 0.1085 & 0.8022 & 0.9986 & T5_WSP & 0.1042 & 0.8071 & 0.9991 \\
\hline T5_CSP & 0.3342 & 0.6261 & 0.9996 & T5_CSP & 0.3891 & 0.6056 & 0.9996 \\
\hline T5_DASP & 0.9008 & 0.3716 & 0.8247 & T5_DASP & 0.9578 & 0.3490 & 0.8370 \\
\hline
\end{tabular}

$H T$ stage directly after harvest, $T 1$ the first month of storage, $T 2$ the second month of storage, $T 3$ the third month of storage, $T 4$ the fourth month of storage, $T 5$ the fifth month of storage

DASP and CSP fractions also increased during the storage period, which could be connected with the activity of sidechain modifying enzymes (arabinanase, galactanase). These enzymes are responsible for removing side chains from pectin, which results in a more linear structure. DASP and CSP did not contain calcium, which is removed during extraction with CDTA. Thus the increase of viscosity of DASP and CSP may be related to hydrogen bonding between smooth pectin chains, as well as to hydrophobic interactions by the methyl groups of adjacent pectin residues (Van Buren 1991). However, FTIR spectra (shown in the supplementary material in Fig. S2) did not allow us to confirm these hypotheses unambiguously since the band related to hydrogen bonding $(3,600-$ $3,000 \mathrm{~cm}^{-1}$ ) was affected by water absorbed during spectra collection. Although calcium content in WSP increased from $0.46 \mu \mathrm{g} / \mathrm{mg}$ AIR in harvest time to $0.69 \mu \mathrm{g} / \mathrm{mg}$ AIR after 5 months, the high degree of methylation (>70\%) suggests that the highest viscosity and its increase during storage was rather not related to ionic cross-linking. Further study is needed to explain these observations.

A pronounced thixotropic effect was observed in the DASP fraction (Fig. 5). The ANOVA showed no significant effect $(p<0.05)$ of term of storage on the size of hysteresis. However, a significant increase occurred between harvest and the last storage stage, from 3 to $14 \%$. Hysteresis loops are proof that the behaviour of the examined DASP fraction is time-dependent, and can be associated with the pectin structure and the interaction between the components of the pectin chain. The DASP fraction is composed of polysaccharides connected to the cell wall with covalent bonds, and thus exhibits a stronger ability to reconstruct the initial gel structure than the WSP fraction, where polysaccharides are linked to the cell wall mainly by non-covalent bonds, or the CSP fraction, which has cross-linking with ionic bonds (Zhang et al. 2005). Recently, a new structure of the DASP fraction has been revealed by atomic force microscope study (Cybulska et al. 2014). DASP molecules extracted from either carrot or apple showed on mica an indubitable ability to self-assemble into a regular network. It was shown that DASP molecules were very linear and separated at around $50-70 \mathrm{~nm}$ by shorter side chains. In the same conditions, WSP were present as short polymers, whereas CSP was present as linear and branched chains. In both WSP and CSP, molecules were separated and any tendency to regularity was reported. Although no mechanism of force-induced change is yet known, such linear structure and ability for self-assembly of DASP molecules may be one reason for the thixotropic properties observed in this experiment.

From a technological point of view, the thixotropic effect has many applications in food processing. Knowledge of the process is very important in prediction of rheological behaviour of material during processes such as stirring, mixing, flow through pipes and relaxing. Therefore, use of the DASP fraction of pectin as an agent for stabilization and gelation could influence a better structure of final products (Tabilo- 


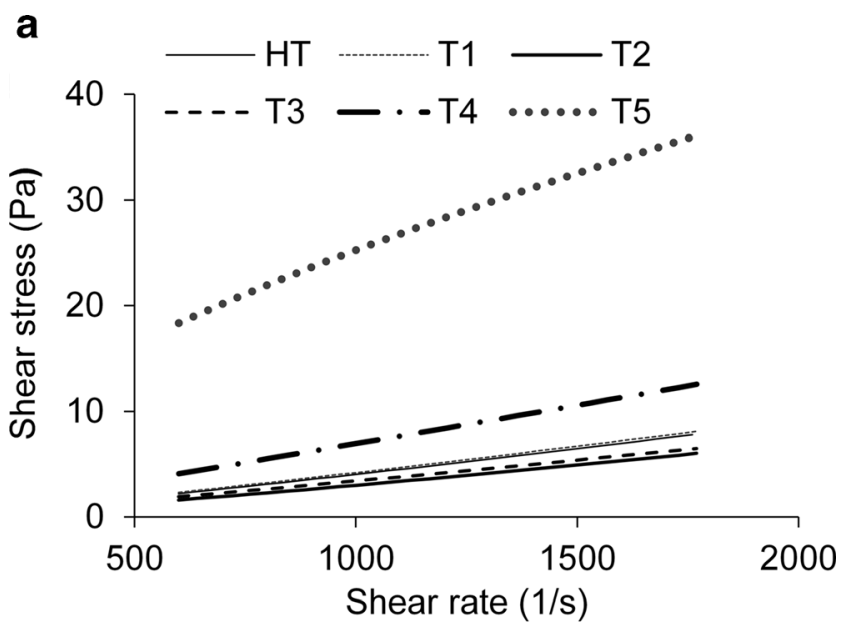

b

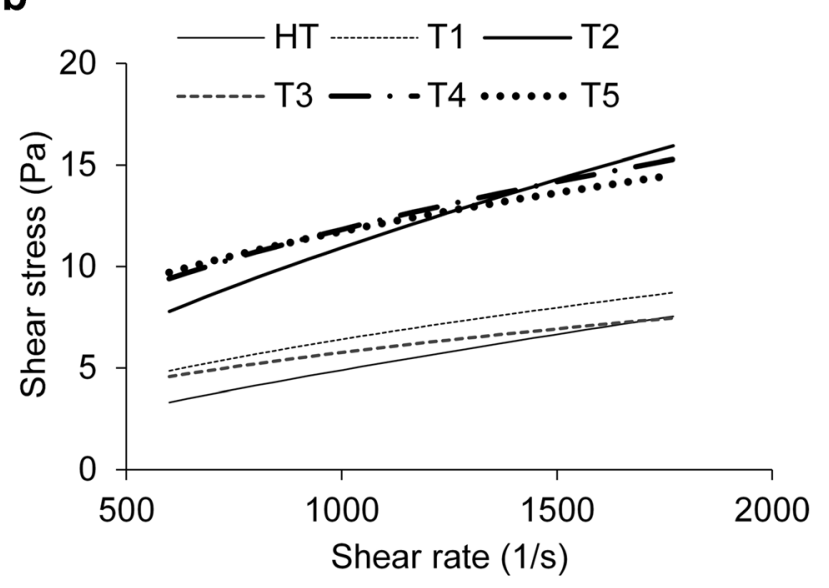

C

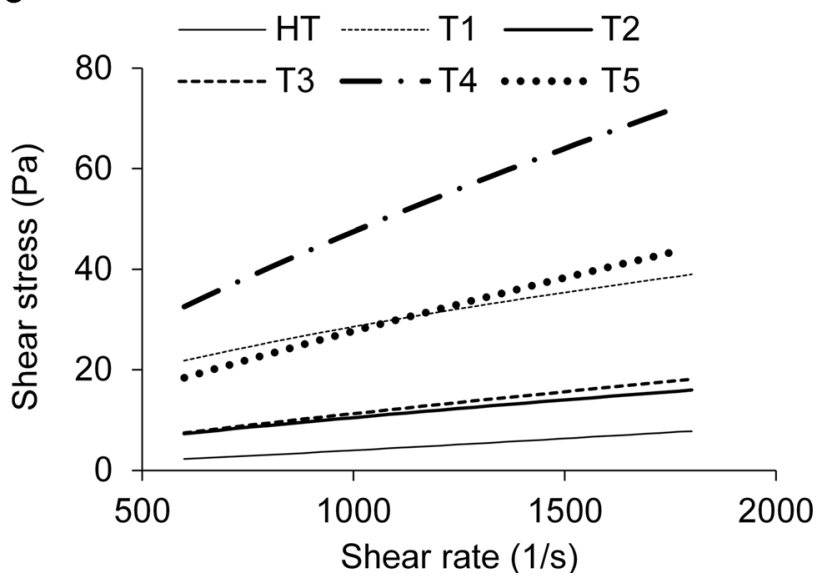

Fig. 3 Shear stress vs. shear rate relationship upward flow curves for (a) WSP (b) CSP (c) DASP fractions of pectin during the storage period (Power law model). HT stage directly after harvest, $T 1$ the first month of storage, $T 2$ the second month of storage, $T 3$ the third month of storage, $T 4$ the fourth month of storage, $T 5$ the fifth month of storage

Munizaga and Barbosa-Cánovas 2005. Similarly, WSP and CSP fractions can be used as a tool to modify food processing and can influence food acceptability. WSP had the highest viscosity, and therefore may be used as a potential thickener. WSP during the harvest time and the first term, and CSP from

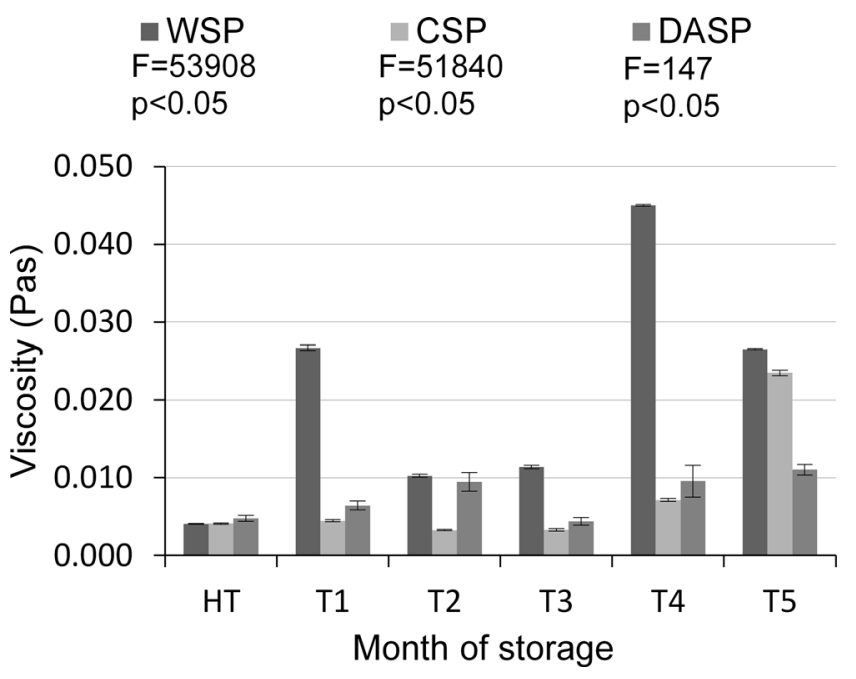

Fig. 4 Viscosity of pectin fractions during storage. $H T$ stage directly after harvest, $T 1$ the first month of storage, $T 2$ the second month of storage, $T 3$ the third month of storage, $T 4$ the fourth month of storage, $T 5$ the fifth month of storage

the harvest time to the third term presented dilatant behaviour; in other words, these fluids can be described as 'shear-thickening'. This means that the materials exhibit extension of viscosity as the shear rate increases. This is a very interesting property of the fluids, which could become significant for food processing.

\section{Conclusions}

This work showed that enzymatic activity of polygalacturonase, $\beta$-galactosidase and $\alpha$-L-arabinofuranosidase increased while

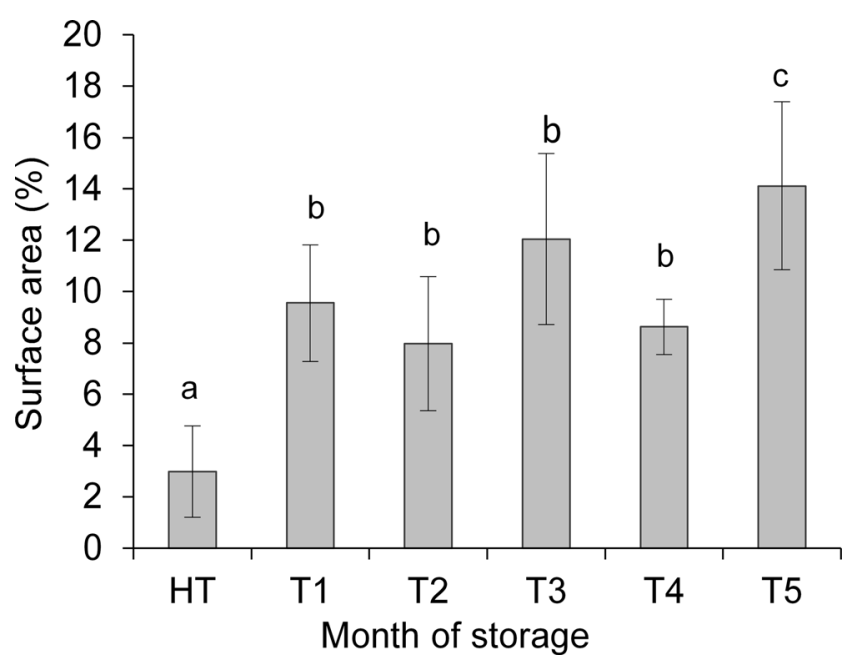

Fig. 5 Hysteresis effect of the flow curves for DASP pectin fraction from 'Nerac' carrot. Mean values (\%) with standard deviations. HT stage directly after harvest, $T 1$ the first month of storage, $T 2$ the second month of storage, $T 3$ the third month of storage, $T 4$ the fourth month of storage, $T 5$ the fifth month of storage. Values with different letters show statistical significance $(p<0.05)$ 
pectinmethyleserases persisted at a constant level with a small increase during postharvest storage of carrot. The degree of methylation in WSP was at a relatively high level and varied in the range of $71.8-78.8 \%$, which may be explained by the formation of new high-methoxyl pectin due to the increase of the total GalA content during storage between 228 and $329 \mu \mathrm{m} /$ mg AIR.

Comparing the three pectin fractions, one may conclude that the highest amount of galacturonic acid was found in the DASP fraction. Galacturonic acid content in CSP increased during the storage; in DASP it persisted at a constant level with slight fluctuations, while in WSP it initially increased and then decreased.

This study showed that rheological properties of pectins in carrot cell walls depend on the solvent used for extraction. WSP had the highest viscosity (maximum 0.045 Pas) compared to CSP (0.023 Pas) and DASP (0.011 Pas). Covalently bonded pectins in cell walls extracted with $\mathrm{Na}_{2} \mathrm{CO}_{3}$ (DASP) revealed thixotropic properties.

The viscosity of the extracted pectins in each studied fraction increased during storage. Although there was no overall statistically significant increase during storage, the thixotropic effect of the DASP fraction apparently also increased (14\% after 5 months of storage) in relation to harvest time (3\%). Based on the Power law model, it may be stated that flow properties (consistency and flow behaviour index) are specific to each fraction. Flow behaviour of DASP did not depend on storage time, whereas WSP and CSP showed a change from dilatant to pseudoplastic flow. These changes in rheological properties may be related to an enzymatic-induced molecular transformation, which promotes a gelling ability.

The results of this study suggest that, depending on the solvent used for extraction and the maturity of carrots, properties of pectins could be tailored for specific applications.

Acknowledgments This work was funded by the Polish National Budget for Science 2012-2014 (Project No. IP2011 007871)) and by the National Centre for Research and Development (Project No. LIDER/23/ 109/L-2/10/NCBiR/2011), and the authors would like to acknowledge their support.

Open Access This article is distributed under the terms of the Creative Commons Attribution License which permits any use, distribution, and reproduction in any medium, provided the original author(s) and the source are credited.

\section{References}

Alimardani-Theuil, P., Gainvors-Claisse, A., \& Duchiron, F. (2011). Yeast: an attractive source of pectinases - from gene expression to potential applications: a review. Process Biochemistry, 46, 1525-1537.

Alonso-Mongán, M., Meijide, F., Jover, A., Rodrígez-Núňez, E., \& Vázquez-Tato, J. (2002). Rheological behavior of an amide pectin. Journal of Food Engineering, 55, 123-129.
Arancibia, R. A., \& Motsenbocker, C. E. (2006). Pectin methylesterase activity in vivo differs from activity in vitro and enhances polygalacturonase-mediated pectin degradation in tabasco pepper. Journal of Plant Physiology, 163, 488-496.

Araya, X. I. T., Hendrickx, M., Verlinden, B. E., Van Buggenhout, S., Smale, N. J., Stewart, C., \& Mawson, A. J. (2007). Understanding texture changes of high pressure processed fresh carrots: a microstructural and biochemical approach. Journal of Food Engineering, 80, 873-884.

Caffall, K. H., \& Mohnen, D. (2009). The structure, function and biosynthesis of plant cell wall pectic polysaccharides. Carbohydrate Research, 344, 1879-1900.

Christiaens, S., Van Boggenhout, S., Chaula, D., Moelants, K., David, C. C., Hofkens, J., Van Loey, A. M., \& Hendrickx, M. E. (2012). In situ pectin engineering as a tool to tailor the consistency and syneresis of carrot purée. Food Chemistry, 133, 146-155.

Cybulska, J., Konstankiewicz, K., \& Zdunek, A. (2010). Nanostructure of natural and model cell wall materials. International Agrophysics, 24, $107-114$.

Cybulska, J., Zdunek, A., \& Konstankiewicz, K. (2011). Calcium effect on mechanical properties of model cell walls and apple tissue. Journal of Food Engineering, 102, 217-223.

Cybulska, J., Pieczywek, P. M., \& Zdunek, A. (2012). The effect of $\mathrm{Ca}^{2+}$ and cellular structure on apple firmness and acoustic emission. European Food Research and Technology, 235, 119-128.

Cybulska, J., Zdunek, A., \& Kozioł, A. (2014). Self-assembled network and physiological degradation of pectins in carrot cell walls. Food Hydrocolloids. doi:10.1016/j.foodhyd.2014.04.032.

Deng, Y., Wu, Y., \& Li, Y. (2005). Changes in firmness, cell wall composition and cell wall hydrolases of grapes stored in high oxygen atmospheres. Food Research International, 38, 769-776.

Dolz, M., Hernández, M. J., Delegido, J., Alfaro, M. C., \& Muñoz, J. (2007). Influence of xanthan gum and locust bean gum upon flow and thixotropic behavior of food emulsions containing modified starch. Journal of Food Engineering, 81, 179-186.

Dubois, M., Gilles, K. A., Hamilton, J. K., Rebers, P. A., \& Smith, F. (1956). Colorimetric method of sugars and related substances. Analytical Chemistry, 28(3), 350-356.

Espinosa-Muňoz, L., Renard, C. M. G. C., Symoneaux, R., Biau, N., \& Cuvelier, G. (2013). Structural parameters that determine the rheological properties of apple puree. Journal of Food Engineering, 119, 619-626.

Fisher, M., \& Amado, R. (1994). Changes in the pectic substances of apples during development and postharvest ripening. Part 1: analysis of alcohol-insoluble residue. Carbohydrate Polymers, 25, 161-166.

Galindo, F. G., Bråthen, E., Knutsen, S. H., Sommarin, M., Gekas, V., \& Sjöholm, I. (2004). Changes in the carrot (Daucus carrota L.cv. Nerac) cell wall during storage. Food Research International, 37, 225-232.

Giovane, A., Servillo, L., Balestrieri, C., Raiola, A., D’Avino, R., Tamburrini, M., Ciardiello, M. A., \& Camardella, L. (2004). Pectin methylesterase inhibitor. Biochimica et Biophysica Acta, $1696,245-252$.

Goulao, L. F., \& Oliveira, C. M. (2008). Cell wall modifications during fruit ripening: when a fruit is not the fruit. Trends in Food Science \& Technology, 19, 4-25.

Harholt, J., Suttangkakul, A., \& Scheller, H. V. (2010). Biosynthesis of pectin. Plant Physiology, 153, 384-395.

Houben, K., Jolie, R. P., Fraeye, I., Van Loey, A. M., \& Hendrickx, M. E. (2011). Comparative study of the cell wall composition of broccoli, carrot and tomato: structural characterization of the extractable pectins and hemicelluloses. Carbohydrate Research, 346, 1105-1111.

Jayani, R. S., Saxena, S., \& Gupta, R. (2005). Microbial pectinolytic enzymes: a review. Process Biochemistry, 40, 2931-2944.

Jolie, R. P., Duvetter, T., Van Loey, A. M., \& Hendrickx, M. E. (2010). Pectin methylesterase and its proteinaceous inhibitor: a review. Carbohydrate Research, 345, 2583-2595. 
Juszczak, L., Witczak, M., Zięba, T., \& Fortuna, T. (2012). Rheological behavior of heated potato starch dispersions. International Agrophysics, 26, 381-386.

Lee, C. H., Moturi, V., \& Lee, Y. (2009). Thixotropic property in pharmaceutical formulations. Journal of Controlled Release, 136, 88-98.

Liang, Z. P., Wang, X. D., Duan, Y. Y., \& Min, Q. (2012). Energy-based model for capillary spreading of power-law liquids on a horizontal plane. Colloids and Surfaces. A: Physicochemical and Engineering Aspects, 403, 155-163.

Ma, J., Lin, Y., Chen, X., Zhao, B., \& Zhang, J. (2014). Flow behavior, thixotropy and dynamical viscoelasticity of sodium alginate aqueous solutions. Food Hydrocolloids, 38, 119-128.

Manrique, G. D., \& Lajolo, F. M. (2002). FT-IR spectroscopy as a tool for measuring degree of methyl esterification in pectins isolated from ripening papaya fruit. Postharvest Biology and Technology, 25(1), 99-107.

Mesbahi, G., Jamalian, J., \& Farahnaky, A. (2005). A comparative study on functional properties of beet and citrus pectins in food systems. Food Hydrocolloids, 19, 731-738.

Ottone, M., Peirotti, M. B., \& Deiber, J. A. (2009). Rheokinetic model to characterize the maturation process of gelatin solutions under shear flow. Food Hydrocolloids, 23, 1342-1350.

Pagán, J., \& Ibarz, A. (1999). Extraction and rheological properties of pectin from peach pomace. Journal of Food Engineering, 39, 193-201.

Penna, A. L. B., Sivieri, K., \& Oliveira, M. N. (2001). Relation between quality and rheological properties of lactic beverages. Journal of Food Engineering, 49, 7-13.

Plaskota, D. (2004). Rheological properties of yogurts depending on their ageing time. ŻYWNOŚĆ. Nauka. Technologia. Jakość, 4 (41) s, 88-99

Renard, C. M. G. C. (2005). Variability in cell wall preparations: quantification and comparison of common methods. Carbohydrate Polymers, 60(4), 515-522.

Schmelter, T., Wientjes, R., Vreeker, R., \& Klaffke, W. (2002). Enzymatic modifications of pectins and the impact on their rheological properties. Carbohydrate Polymers, 47, 99-108.
Selvendran, R. R., \& O’Neill, M. A. (1987). Isolation and analysis of cell walls from plant material. Methods of Biochemical Analysis, 32, 25 153.

Tabilo-Munizaga, G., \& Barbosa-Cánovas, G. V. (2005). Rheology for the food industry. Journal of Food Engineering, 67, 147-156.

Torres, S., Sayago, J., Ordonez, R. M., \& Isla, M. I. (2011). A colorimetic method to quantify endo-polygalacturonase activity. Enzyme and Microbial Technology, 48, 123-128.

Van Buren, J. P. (1991). Function of Pectin in Plant Tissue Structure and Firmness. In R. H. Walter (Ed.), The chemistry and technology of pectin (pp. 12-13). San Diego: Academic.

Wei, J., Ma, F., Shi, S., Qi, X., Zhu, X., \& Yuan, J. (2010). Changes and postharvest regulation of activity and gene expression of enzymes related to cell wall degradation in ripening apple fruit. Postharvest Biology and Technology, 56, 147-154.

Willats, W. G. T., Knox, J. P., \& Mikkelsen, J. D. (2006). Pectin: new insights into an old polymer are starting to gel. Trends in Food Science \& Technology, 17, 97-104.

Yang, H., An, H., Feng, G., Li, Y., \& Lai, S. (2005). Atomic force microscopy of the water-soluble pectin of peaches during storage. European Food Research and Technology, 220, 587-591.

Yang, H., Feng, G., An, H., \& Li, Y. (2006). Microstructure changes of sodium carbonate-soluble pectin of peach by AFM during controlled atmosphere storage. Food Chemistry, 94, 179-192.

Zdunek, A., \& Cybulska, J. (2011). Relation of biospeckle activity with quality attributes of apples. Sensors, 11, 6317-6327.

Zhang, L. M., Zhou, J. F., \& Hui, P. S. (2005). Thickening, shear thinning and thixotropic behavior of a new polysaccharide-based polyampholyte in aqueous solutions. Colloids and Surfaces, A: Physicochemical and Engineering Aspects, 259, 189-195.

Zhang, L., Chen, F., Yang, H., Ye, X., Sun, X., Liu, D., Yang, B., An, H., \& Deng, Y. (2012). Effects of temperature and cultivar on nanostructural changes of water soluble pectin in peaches. Carbohydrate Polymers, 87, 816-821. 